\title{
Effect of Modified Clinical Pathway Guidelines on Congestive Heart Failure Patient's satisfaction at Coronary Care Unit
}

\author{
Ragaa Dahi Mohamed ${ }^{1}$, Warda Youssef Mohamed ${ }^{2}$, Mervat Anwar AbdEl-Aziz ${ }^{3}$ \& Hatem Abdel-Rahman Helmy ${ }^{4}$. \\ 1- Assistant lecturer of Critical Care \&Emergency Nursing, Faculty of Nursing, South Valley University, Qena. \\ 2- Professor of Critical Care \& Emergency Nursing, Faculty of Nursingm Cairo University, Egypt. \\ 3- Assist Professor of Critical Care \& Emergency Nursing, Faculty of Nursing, Assuit University, Egypt. \\ 4- Professor of Cardiovascular Medicine, Faculty of Medicine- Assuit University, Egypt.
}

\begin{abstract}
Background: Congestive heart failure patients at coronary care unit suffer from many problems, which might endanger their life as increased anxiety level which originated from disease process and the actual care they receive was complex. Modified Care pathway guidelines are tools that enhance the patient quality of care by decreasing level of anxiety which may lead to increasing patient satisfaction. Therefore, the aim of this study is to evaluate effect of modified clinical pathway guidelines on congestive heart failure patients' satisfaction at Coronary Care Unit. Design: Quasi-experimental research design. Setting: Coronary Care Unit at Assuit University Hospitals. Sample: sixty adult males and females' critically ill patients' who divided into two equal and matched groups (study and control). Tools:- Three tools; Tool I: Personal and medical datasheet, Tool II Assessment of patient anxiety using state-trait anxiety inventory, and Tool III Patients' Satisfaction Scale. Results: Finding of this study supported stated research hypotheses with statistical significant difference between study and control groups regarding total mean of anxiety score at $6^{\text {th }}$ day of intervention were $(39.6 \pm 6.7,44.87 \pm 4.54)$ respectively as well as $(50 \%)$ of study group patients were very satisfied as compared with (3.3\%) of control group. Conclusion: Applying modified clinical pathway guidelines significantly reduce anxiety level in congestive heart failure critically ill patients and improve patient's satisfaction. Recommendation: Conducting training programs about importance of modified clinical pathway guidelines implementation for all health care providers.
\end{abstract}

Key words: Congestive Heart Failure, Coronary Care unit, Modified Clinical Pathway Guidelines \& Patient's Satisfaction.

\section{Introduction}

Congestive heart failure (CHF), affects large number of population with frequent new cases being diagnosed each year. It is a complex syndrome that is associated with profound disease morbidity and mortality and has an adverse impact on the quality of life (Chen-Scarabelli et al., 2015). Statistics of coronary care unit (CCU) at Assuit University Hospital in year 2014 of revealed that the number of patients admitted to coronary care unit CCU is 96 with congestive heart failure (Hospital records of Assuit University 2014).

Patients with congestive heart failure often have higher rates of anxiety compared to the general population. The prevalence of major depression in CHF patients is reported to be about 15-22\%. Depression is an independent risk factor for poor prognosis in CHF patients, and has been significantly associated with higher readmission rates, prolonged hospitalization and reduced functional status (Smita et al., 2013).

Patient's satisfaction is one of the two main components of care quality which includes respect for the patient, understanding his needs and providing services. Patient satisfaction is a major indicator of quality care. Thus quality of work can be assessed by mapping out patient satisfaction with nursing care. Nursing services is one of the most important components of hospital services which has two major objectives; nursing care of sick patient and prevention of disease and promotion of health. Nurses form a very important group, which is largest single technical group of personal engaged in hospital care next to doctors (Tang, Soong \& Lim, 2013).

It thus becomes increasingly important that clinicians, patients and caregivers realize that the presence of major anxiety is not a standard part of living with CHF. Since anxiety increases the risk of ischemic heart diseases and overall cardiac morbidity and mortality, it is important that considerable effort be directed for their safe and effective management. Addressing the problems of anxiety disorders in CHF patients may help improve these patients' quality of life and improve outcomes in this patients (Debasree, Smita, Nitin, \& James 2013).

Clinical Pathways are structured and multidisciplinary care plans used to detail essential steps and timing in the care of patients with a specific clinical problem" (Kinsman et al., 2010). Clinical Pathways are typically developed by providers using nationally recognized clinical practice guidelines, which are modified as needed by advisory boards or 
committees. Some providers have created Clinical Pathways independently, often using clinical practice guidelines as a starting point and making modifications based on their own clinical experience (DeMartino \& Larsen, 2012).

Clinical pathway guidelines have become a popular tool to enhance the quality of care by improving patient outcomes, promoting patient safety, increasing patient satisfaction, and optimizing the use of resources. The researcher performed a disease specific systematic review to determine how care pathways in the hospital treatment of heart failure affect in-hospital mortality, length of in-hospital stay, readmission rate and hospitalization cost when compared with standard care (SevalKul, 2012).

\section{Significance of the study}

Statistics of coronary care unit (CCU) at Assuit University Hospital in year 2014 of revealed that the number of patients admitted to coronary care unit $\mathrm{CCU}$ is 96 with congestive heart failure (Hospital records of Assuit University 2014).

\section{Aim of the study}

To evaluate effect of modified clinical pathway guidelines on congestive heart failure patients' satisfaction at Coronary Care Unit.

\section{Research question}

What is effect of modified clinical pathway guidelines on congestive heart failure patients' satisfaction at Coronary Care Unit?

\section{Operational Definition:}

Modified Clinical Pathway guidelines are group of guidelines formulated from combination of two clinical pathways. It consisted of four stages; admission stage covered first twenty hours, acute stage covered the second two days after the first day, maintenance stage covered the three days after the acute stage and four stage called discharge criteria.

Research hypotheses: To fulfill this aim the following research hypotheses were formulated:

1)Critically ill Congestive heart failure patients who are subjected to the modified clinical pathway guidelines will decrease level of anxiety than patients who receive the routine hospital care only.

2)Critically ill Congestive heart failure patients who are subjected to the modified clinical pathway guidelines will have higher level of satisfaction with care process than patients who receive the routine hospital care only.

\section{Patient \& Method}

Research design: A quasi-experimental research design has been used for this study. This design is used to explain relation, clarify certain events happened or both. This design is also a mean of examining causal relation, quasi-experimental research have insufficient control when compared with experimental research design in at least one of three area; 1) Manipulation of the treatment variables 2) Manipulation of the setting 3) Selection of subjects. In clinical nursing studies, subjects are frequently not randomly selected but the samples are convenient. Thus, nurse researches conduct more quasi-experimental studies (Goodrick, 2014).

Setting: The study was conducted in Coronary Care Unit that located on heart center at Assuit University Hospital. Which situated in the second floor of heart center, and it consisted of three rooms; two of them consisted of 12 beds, six beds in every one, and four beds in the third room.

\section{Subjects}

A convenience sample of 60 adult males and females of congestive heart failure patients admitted in $\mathrm{CCU}$ during period of study for nine months started from August 2015 to April 2016. The sample recruited equally into two matched groups; control and study (30 patients for each).

Matching criteria: Age, Sex, Diagnosis, and Comorbidity diseases (e.g. diabetes mellitus and hypertension)

Study tools: three tools were formulated to collect data for control and study group patients after reviewing the related literatures.

\section{Tool I: Personal and medical data sheet}

This tool was developed by the researcher after reviewing the related literature's(Gonce and Dorrie, 2013) to assess patient's demographic and health relevant data, it comprised two parts;

Part I: Demographic data: it includes age, sex, occupation, level of education, and marital status.

Part I: Medical data as medical diagnosis, and type of allergy.

Tool II: Assessment of patient anxiety using StateTrait Anxiety Inventory (STAI)

Anxiety assessment had done using this scale by (Julian, 2011). The STAI is an administrated analysis of reported anxiety symptoms. This inventory measures two dimensions of anxiety, first: anxiety as a state and second anxiety as a trait. Each dimension of the inventory consists of 20 questions; there are ten positive questions and other ten negative questions. Every question is scored on a scale of one to four (Not at all, Some What, Moderately so, $\&$ Very much so). The total score value ranges from 20 to 80, the higher score the higher anxiety level.

Tool III: Patients' Satisfaction Scale about Caring Process

This tool was used to assess the patient satisfaction about caring process. The tool adopted by (Salisbury et al., 2005) and translated to Arabic language and tested for validity and reliability by Rashad, (2011). 
This tool consist of 15 items (four items related to hospital administration, five items related to caring by nursing team, three items related to caring by medical team, and three items relation to hospital outcomes). admission process, clarity of admission information, adequacy of information given to family about patient's condition and needs, adequacy of information about duration of hospital stay, sufficiency of information concerning the medical condition, sufficiency of information regarding medication administration, adequacy of coordination of care among health care team, adequacy of nurse's knowledge about caring process, adequacy of nurses explanation about the overall part of care, clarity of nurse's explanation, adequacy of doctor's explanation of patient condition, adequacy of physician's knowledge about caring process, proper timing of discharge instructions, arrangement of discharge, adequacy of overall quality of care and services.

Every participant expressed his satisfaction for each care item on a 5 point likert type scale ranging from 1 to 5, a score of (1) very dissatisfied, (2) dissatisfied, (3) neutral, (4) satisfied and (5) very satisfied.

\section{Method}

The study conducted though out three main phases, which were preparatory phase, implementation phase, and evaluation phase.

\section{Preparatory phase}

- A written approval was obtained from the hospital administrative authority to collect the necessary data.

- Content validity of the tools was done by five experts in the related fields as cardiology medicine and the essential modifications had done accordingly.

- A pilot study was carried out for $10 \%$ of patients' sample (Six patients) to check and ensure clarity, feasibility and applicability of the tools. There were no necessary modifications were done, so pilot study subjects included in the actual study subjects.

- The Reliability of assessment tools were tested using Cronbach's alpha $(r=0.834,0.731 \& 0.843)$.

\section{Ethical considerations}

- Research proposal was approved from Ethical Committee in the Faculty of Nursing -Assuit.

- The study was following common ethical principles in clinical research.

- Written consent obtained from patients or guardian that are willing to participate in the study after explaining the nature and purpose of the study

- Patient assured that the data of this research will not be reused without a second permission.

- Confidentiality and anonymity assured.
- Patients have the right to refuse to participate and or withdraw from the study without any rationale at any time.

Modified Clinical Pathway Guidelines Establishment: This guidelines procedures and checklists contain the recommended nursing care procedures for patients with $\mathrm{CHF}$ to be used with pathway as a guide for detailed procedure steps. It was prepared by researcher due to combination of two clinical pathways using relevant literatures and tested for content validity by the jury members.

Modified Clinical pathway guidelines team: Clinical pathway committee comprised of head nurse of coronary care unit, assistant head nurse, cardiologist, and professor of critical care nursing. The established pathway examined by professionals in the field of services and education to test for content validity.

Description of Modified Clinical pathway guidelines; it consisted of four stages (Admission, Acute, Maintenance and Discharge criteria) adapted from (Canadian Cardiovascular Society (CCS)\& Bruce, 2011): The clinical pathway team and the researcher observed and managed the patient in the four stages; 1) Admission stage, it takes the first 24 hours and made patient assessment every $15 \mathrm{~min}$ in $1^{\text {st }}$ hour q $30 \mathrm{~min}$ in $2^{\text {nd }}$ hour then $\mathrm{q}$ 1hour after that, 2) Acute care stage that targets two days, in this stage made patient assessment every 4 hours, and 3) Maintenance stage that targets another three days, in this stage made patient assessment twice per day, and stage 4) Discharge criteria. The clinical outcomes of the patients assessed every day until six day, the researcher made interview with the patient's to know the level of satisfaction about the care process and condition of the patients by using tool III.

Development of $\mathrm{CHF}$ illustrated educational materials: A handout in a form of illustrated colored educational booklet for CHF patients was developed in Arabic language by researcher to help the patient to know peripherally and simple about his disease, it's complications, signs, symptom, causes, diagnosis, treatment, medication and know medication dose, side effects of medication, diet, exercise follow up and danger signs.

Implementation phase: Data of the current study were collected from August 2015 to April 2016, once an official permission was obtained from the director of the Coronary Care Unit (CCU).

Procedure

Assessment of current practice (assess hospital routine as baseline for clinical pathway).

- Data collected from control group first then from the study group using three tools. The control group subjects received routine hospital intervention only while the study group subjects was undergoing 
developed modified clinical pathway guidelines in addition to hospital routine care.

- Initial assessment of every patient in control group was done on admission day as baseline data and daily using tool I during CCU staying.

\section{Data collection of the control group}

Data collection started with control group subjects who were managed according to usual hospital routine care only.

Following the control group, the researcher informed CCU staff about the study using various approaches, the researcher gave a written copy of the study and the designed modified clinical pathway guidelines to pathway team, after that, the researcher interviewed each clinical pathway team members to discuss unclear points and answer to all questions as well as to ensure consent to participate in the intervention process and approved the designed modified clinical pathway guidelines, also the researcher discussed the aim and principal of the study.

Modified clinical pathway guidelines implementing and data collection from the pathway group subjects:

- Data collection from the pathway group who were subjected to the modified clinical pathway guidelines implemented by researcher and health care provider in Coronary Care Unit (CCU). It was carried out after complementation of control group data collection.

- Orientation session provided to health care providers about purpose plus process of implementing modified clinical pathway guidelines and after that check the work with them.

- The researcher acted as a coordinator and divided the modified clinical pathway guidelines into timed tasks after reviewing the current practices and recent related literatures.

- The established modified clinical pathway guidelines implemented on studied group by the training care provider group from admission day (first day as baseline data), and daily for five days, under the supervision of the researcher.

\section{Patients' assessment:}

study group assessed from admission as baseline data using tool 1 and daily for five days during the three shifts (morning, evening and night shift) and then taken mean readings of these shifts daily.

- The demographic data were completed for all study group patients on admission as baseline data.

- Patient's anxiety level assessed at first day (admission day) then repeated at $6^{\text {th }}$ day using tool II, but repeated for study group after psychological support.
- Satisfaction scale for CHF patients made it in the $6^{\text {th }}$ day using tool III.

For psychosocial support and education part:

On admission, teaching focused on the reasons for admission with family of patients, at the second day by introduced patient pathway, started teaching checklist; give patient and/or Family health teaching about congestive heart failure using the developed educational booklet. Health education about medication, I spent with each patient about twenty minutes given explanation, after that put time for patients ask questions and anything concerning care process. At $4^{\text {th }}$ to $6^{\text {th }}$ days reviewed patient Pathway, Continued/Completed teaching checklist, review information about congestive heart failure and Assess patient knowledge/answer Questions; This part help patient to increase satisfaction level, and also decrease anxiety level about disease process.

\section{Evaluating Phase}

- Evaluate congestive heart failure patient's care by measuring patient's anxiety at $\left(1^{\text {st }}, 4^{\text {th }} \& 6^{\text {th }}\right)$ days.

- Evaluate congestive heart failure patient's care by measuring patient's satisfaction at the day of discharge.

Statistical analysis:

- Data were computerized and analyzed by computer programmed SPSS (ver.20). Data were presented using descriptive statistics in the form of frequencies and percentages for qualitative variables, and means \pm standard deviations for qualitative variables. Quantitative continuous data were compared using Independent samples t- test for comparisons among two groups. Qualitative variables were compared using chi-square test to determine significance.

- The critical value of the tests "P" was considered statistically significant when P less than 0.05 . 


\section{Results}

Table (1): Distribution of demographic characteristic and medical data regarding to patient with congestive heart failure in both group.

\begin{tabular}{|c|c|c|c|c|c|c|}
\hline \multirow{2}{*}{\multicolumn{2}{|c|}{ Demographic characteristic }} & \multicolumn{2}{|c|}{$\begin{array}{c}\text { Study group } \\
(n=30)\end{array}$} & \multicolumn{2}{|c|}{$\begin{array}{c}\text { Control group } \\
(\mathbf{n}=\mathbf{3 0})\end{array}$} & \multirow[t]{2}{*}{ P. value } \\
\hline & & No. & $\%$ & No. & $\%$ & \\
\hline \multirow{5}{*}{ Age } & $20-30$ years & 0 & 0.0 & 0 & 0.0 & \multirow{4}{*}{0.123} \\
\hline & $31-40$ years & 4 & 13.3 & 6 & 20.0 & \\
\hline & $41-50$ years & 8 & 26.7 & 6 & 20.0 & \\
\hline & $51-60$ years & 18 & 60 & 18 & 60.0 & \\
\hline & Mean \pm SD & \multicolumn{2}{|c|}{$51.7 \pm 8.7$} & \multicolumn{2}{|c|}{$50.3 \pm 9.6$} & 0.559 \\
\hline \multirow[t]{2}{*}{ Sex } & Male & 19 & 63.3 & 13 & 43.3 & \multirow{2}{*}{0.121} \\
\hline & Female & 11 & 36.7 & 17 & 56.7 & \\
\hline \multirow{4}{*}{$\begin{array}{l}\text { Marital } \\
\text { status }\end{array}$} & Married & 26 & 86.6 & 26 & 86.7 & \multirow{4}{*}{0.721} \\
\hline & Single & 2 & 6.7 & 1 & 3.3 & \\
\hline & Divorced & 2 & 6.7 & 2 & 6.7 & \\
\hline & Widow & 0 & 0.0 & 1 & 3.3 & \\
\hline \multirow{4}{*}{ Diagnosis } & $\begin{array}{l}\text { Congestive heart failure } \\
(\mathrm{CHF})+\text { Diabetes Mellitus }\end{array}$ & 8 & 26.7 & 10 & 33.3 & \multirow{4}{*}{0.963} \\
\hline & CHF+ Hypertension & 7 & 23.3 & 6 & 20.0 & \\
\hline & CHF+ Ischemic Heart Diseases & 10 & 33.3 & 12 & 40.0 & \\
\hline & $\begin{array}{l}\text { CHF+ Others as(appendectomy } \\
\& \text { hysterectomy }\end{array}$ & 5 & 30.0 & 2 & 30.0 & \\
\hline \multirow{3}{*}{ Allergies } & Food allergy & 11 & 36.7 & 11 & 36.7 & \multirow{3}{*}{0.878} \\
\hline & Drug allergy & 4 & 13.3 & 3 & 10.0 & \\
\hline & No allergies & 15 & 50.0 & 16 & 53.3 & \\
\hline
\end{tabular}

Table (2): Mean anxiety regarding patient with congestive heart failure by using Patient's State-Trait Anxiety scale in both group.

\begin{tabular}{|l|c|c|c|}
\hline \multirow{2}{*}{\multicolumn{1}{|c|}{ Variables $/$ days }} & $\begin{array}{c}\text { Study group } \\
\mathbf{n = 3 0}\end{array}$ & $\begin{array}{c}\text { Control group } \\
\mathbf{n = 3 0}\end{array}$ & \multirow{2}{*}{ P. value } \\
\cline { 2 - 3 } & mean \pm SD & mean \pm SD & \\
\hline State anxiety scale on $1^{\text {st }}$ day & $51.07 \pm 3.2$ & $50.73 \pm 2.95$ & 0.677 \\
\hline State anxiety scale on $4^{\text {th }}$ day & $44.6 \pm 4.1$ & $48.3 \pm 6.7$ & $0.012^{*}$ \\
\hline State anxiety scale on $6^{\text {th }}$ day & $39.6 \pm 6.2$ & $44.87 \pm 4.54$ & $0.001^{* *}$ \\
\hline
\end{tabular}

- chi-square test * Statistically significant difference $(p<0.05)^{* *}$ statistically significant difference $(p<0.01)$.

In relation to hypothesis two, this states that: Critically ill Congestive heart failure patients who are subjected to the modified clinical pathway guidelines will have higher level of satisfaction with care process than patients who receive the routine hospital care only. (Tables 3-6 and figure 1 are related to this hypothesis) 
Table (3): Distribution between study and control groups in relation to patient satisfaction by hospital administrative care

\begin{tabular}{|c|c|c|c|c|c|}
\hline \multirow{2}{*}{$\begin{array}{c}\text { Items of satisfaction by Hospital administrative } \\
\text { care }\end{array}$} & \multicolumn{2}{|c|}{$\begin{array}{c}\text { Study group } \\
\mathbf{n}=\mathbf{3 0}\end{array}$} & \multicolumn{2}{|c|}{$\begin{array}{c}\text { Control group } \\
\mathbf{n}=\mathbf{3 0}\end{array}$} & \multirow[t]{2}{*}{ P. value } \\
\hline & No & $\%$ & No & $\%$ & \\
\hline \multicolumn{6}{|c|}{ Admission process to hospital was completed smoothly without any difficulties. } \\
\hline Very dissatisfied & 1 & 3.3 & 2 & 6.7 & \multirow{5}{*}{0.168} \\
\hline Dissatisfied & 2 & 6.7 & 1 & 3.3 & \\
\hline Neutral & 5 & 16.7 & 13 & 43.3 & \\
\hline Satisfied & 12 & 40.0 & 6 & 20.0 & \\
\hline Very satisfied & 10 & 33.3 & 8 & 26.7 & \\
\hline \multicolumn{6}{|c|}{$\begin{array}{l}\text { I was clearly informed at all times regarding, what was happening while waiting to be admitted to } \\
\text { coronary care unit (CCU). }\end{array}$} \\
\hline Very dissatisfied & 3 & 10.0 & 1 & 3.3 & \multirow{5}{*}{0.344} \\
\hline Dissatisfied & 5 & 16.7 & 6 & 20.0 & \\
\hline Neutral & 12 & 40.0 & 18 & 60.0 & \\
\hline Satisfied & 6 & 20.0 & 4 & 13.3 & \\
\hline Very satisfied & 4 & 13.3 & 1 & 3.3 & \\
\hline \multicolumn{6}{|c|}{ My family was kept well informed about my condition and needs. } \\
\hline Very dissatisfied & 0 & 0.0 & 4 & 13.3 & \multirow{5}{*}{$0.000 * *$} \\
\hline Dissatisfied & 2 & 6.7 & 10 & 33.3 & \\
\hline Neutral & 5 & 16.7 & 9 & 30.0 & \\
\hline Satisfied & 3 & 10.0 & 5 & 16.7 & \\
\hline Very satisfied & 20 & 66.7 & 2 & 6.7 & \\
\hline \multicolumn{6}{|l|}{ The discharge arrangement was handled smoothly. } \\
\hline Very dissatisfied & 1 & 3.3 & 16 & 53.3 & \multirow{5}{*}{$0.000 * *$} \\
\hline Dissatisfied & 2 & 6.7 & 7 & 23.3 & \\
\hline Neutral & 1 & 3.3 & 4 & 13.3 & \\
\hline Satisfied & 11 & 36.7 & 2 & 6.7 & \\
\hline Very satisfied & 15 & 50.0 & 1 & 3.3 & \\
\hline
\end{tabular}

Table (4): Comparison between study and control groups in relation to patient satisfaction about caring process by nursing team.

\begin{tabular}{|c|c|c|c|c|c|}
\hline \multirow{2}{*}{ Items of Caring satisfaction by nursing team } & \multicolumn{2}{|c|}{$\begin{array}{c}\text { Study group } \\
\mathbf{n}=\mathbf{3 0}\end{array}$} & \multicolumn{2}{|c|}{ 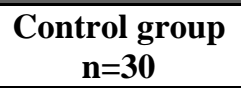 } & \multirow[t]{2}{*}{ P. value } \\
\hline & No & $\%$ & No & $\%$ & \\
\hline \multicolumn{6}{|c|}{ I received sufficient information regarding my medication administration. } \\
\hline Very dissatisfied & 0 & 0.0 & 2 & 6.7 & \multirow{5}{*}{$0.000 * *$} \\
\hline Dissatisfied & 2 & 6.7 & 10 & 33.3 & \\
\hline Neutral & 1 & 3.3 & 13 & 43.3 & \\
\hline Satisfied & 9 & 30.0 & 4 & 13.3 & \\
\hline Very satisfied & 18 & 60.0 & 1 & 3.3 & \\
\hline \multicolumn{6}{|c|}{ Nurses always seemed to be knowledgeable what they were doing and what to do next. } \\
\hline Very dissatisfied & 0 & 0.0 & 4 & 13.3 & \multirow{5}{*}{$0.000 * *$} \\
\hline Dissatisfied & 1 & 3.3 & 12 & 40.0 & \\
\hline Neutral & 2 & 6.7 & 10 & 33.3 & \\
\hline Satisfied & 9 & 30.0 & 3 & 10.0 & \\
\hline Very satisfied & 18 & 60.0 & 1 & 3.3 & \\
\hline \multicolumn{6}{|l|}{ Nurses explained the overall plan for my care to me. } \\
\hline Very dissatisfied & 1 & 3.3 & 2 & 6.7 & \multirow{2}{*}{$0.000^{* *}$} \\
\hline Dissatisfied & 1 & 3.3 & 10 & 33.3 & \\
\hline
\end{tabular}




\begin{tabular}{|c|c|c|c|c|c|}
\hline \multirow[t]{2}{*}{ Items of Caring satisfaction by nursing team } & \multicolumn{2}{|c|}{$\begin{array}{c}\text { Study group } \\
\mathbf{n}=\mathbf{3 0}\end{array}$} & \multicolumn{2}{|c|}{$\begin{array}{c}\text { Control group } \\
\mathbf{n}=\mathbf{3 0}\end{array}$} & \multirow[t]{5}{*}{ P. value } \\
\hline & No & $\%$ & No & $\%$ & \\
\hline Neutral & 1 & 3.3 & 14 & 46.7 & \\
\hline Satisfied & 7 & 23.3 & 2 & 6.7 & \\
\hline Very satisfied & 20 & 66.7 & 2 & 6.7 & \\
\hline \multicolumn{6}{|c|}{ Nurses explained the care they carried out in a way that I could understand. } \\
\hline Very dissatisfied & 1 & 3.3 & 1 & 3.3 & \multirow{5}{*}{$0.000^{* *}$} \\
\hline Dissatisfied & 1 & 3.3 & 10 & 33.3 & \\
\hline Neutral & 3 & 10.0 & 15 & 50.0 & \\
\hline Satisfied & 0 & 0.0 & 2 & 6.7 & \\
\hline Very satisfied & 25 & 83.3 & 2 & 6.7 & \\
\hline \multicolumn{6}{|c|}{ I and my family were advised of my discharge on time that allowed me to do all necessary preparations. } \\
\hline Very dissatisfied & 1 & 3.3 & 5 & 16.7 & \multirow{5}{*}{$0.000 * *$} \\
\hline Dissatisfied & 3 & 10.0 & 9 & 30.0 & \\
\hline Neutral & 4 & 13.3 & 11 & 36.7 & \\
\hline Satisfied & 14 & 46.7 & 2 & 6.7 & \\
\hline Very satisfied & 8 & 26.7 & 3 & 10.0 & \\
\hline
\end{tabular}

Table (5): Comparison between study and control groups as regards to patient satisfaction about caring process by medical team.

\begin{tabular}{|c|c|c|c|c|c|}
\hline \multirow{2}{*}{ Items of Caring by medical team } & \multicolumn{2}{|c|}{$\begin{array}{c}\text { Study group } \\
\mathbf{n}=\mathbf{3 0}\end{array}$} & \multicolumn{2}{|c|}{$\begin{array}{c}\text { Control group } \\
\mathbf{n}=\mathbf{3 0}\end{array}$} & \multirow{2}{*}{ P. value } \\
\hline & No & $\%$ & No & $\%$ & \\
\hline \multicolumn{6}{|c|}{ I received sufficient information concerning my medical condition. } \\
\hline Very dissatisfied & 1 & 3.3 & 1 & 3.3 & \multirow{5}{*}{$0.000 * *$} \\
\hline Dissatisfied & 1 & 3.3 & 11 & 36.7 & \\
\hline Neutral & 2 & 6.7 & 14 & 46.7 & \\
\hline Satisfied & 10 & 33.3 & 3 & 10.0 & \\
\hline Very satisfied & 16 & 53.3 & 1 & 3.3 & \\
\hline \multicolumn{6}{|c|}{ Doctors told me all I wanted to know about my condition. } \\
\hline Very dissatisfied & 3 & 10.0 & 2 & 6.7 & \multirow{5}{*}{0.595} \\
\hline Dissatisfied & 2 & 6.7 & 3 & 10.0 & \\
\hline Neutral & 5 & 16.7 & 10 & 33.3 & \\
\hline Satisfied & 8 & 26.7 & 6 & 20.0 & \\
\hline Very satisfied & 12 & 40.0 & 9 & 30.0 & \\
\hline \multicolumn{6}{|c|}{ Physician seemed to be to be knowledgeable what was happening at all stages during my care. } \\
\hline Very dissatisfied & 0 & 0.0 & 0 & 0.0 & \multirow{5}{*}{0.468} \\
\hline Dissatisfied & 0 & 0.0 & 0 & 0.0 & \\
\hline Neutral & 2 & 6.7 & 4 & 13.3 & \\
\hline Satisfied & 13 & 43.3 & 9 & 30.0 & \\
\hline Very satisfied & 15 & 50.0 & 17 & 56.7 & \\
\hline
\end{tabular}

$*$ Statistically significant difference $(p<0.05) \quad * *$ Statistically significant difference $(p<0.01)$

- chi-square test 
Table (6): Comparison between study and control groups regarding to patient satisfaction about caring process to achieve hospital outcomes.

\begin{tabular}{|c|c|c|c|c|c|}
\hline \multirow[t]{2}{*}{ Hospitalization outcomes } & \multicolumn{2}{|c|}{$\begin{array}{c}\text { Study group } \\
\mathbf{n}=\mathbf{3 0}\end{array}$} & \multicolumn{2}{|c|}{$\begin{array}{c}\text { Control group } \\
\mathbf{n}=\mathbf{3 0}\end{array}$} & \multirow[t]{2}{*}{ P. value } \\
\hline & No & $\%$ & No & $\%$ & \\
\hline \multicolumn{6}{|c|}{ I was well informed about how long I would stay in hospital. } \\
\hline Very dissatisfied & 2 & 6.7 & 6 & 20.0 & \multirow{5}{*}{$0.000 * *$} \\
\hline Dissatisfied & 1 & 3.3 & 9 & 30.0 & \\
\hline Neutral & 6 & 20.0 & 12 & 40.0 & \\
\hline Satisfied & 3 & 10.0 & 2 & 6.7 & \\
\hline Very satisfied & 18 & 60.0 & 1 & 3.3 & \\
\hline \multicolumn{6}{|c|}{$\begin{array}{l}\text { The coordination of care among doctors, nurses and CCU staff was good, what took care of me during } \\
\text { my stay. }\end{array}$} \\
\hline Very dissatisfied & 2 & 6.7 & 6 & 20.0 & \multirow{5}{*}{$0.000 * *$} \\
\hline Dissatisfied & 1 & 3.3 & 7 & 23.3 & \\
\hline Neutral & 7 & 23.3 & 15 & 50.0 & \\
\hline Satisfied & 14 & 46.7 & 2 & 6.7 & \\
\hline Very satisfied & 6 & 20.0 & 0 & 0.0 & \\
\hline \multicolumn{6}{|c|}{ Overall the quality of care and service I received were good. } \\
\hline Very dissatisfied & 2 & 6.7 & 4 & 13.3 & \multirow{5}{*}{$0.000 * *$} \\
\hline Dissatisfied & 1 & 3.3 & 6 & 20.0 & \\
\hline Neutral & 2 & 6.7 & 10 & 33.3 & \\
\hline Satisfied & 2 & 6.7 & 9 & 30.0 & \\
\hline Very satisfied & 23 & 76.7 & 1 & 3.3 & \\
\hline
\end{tabular}

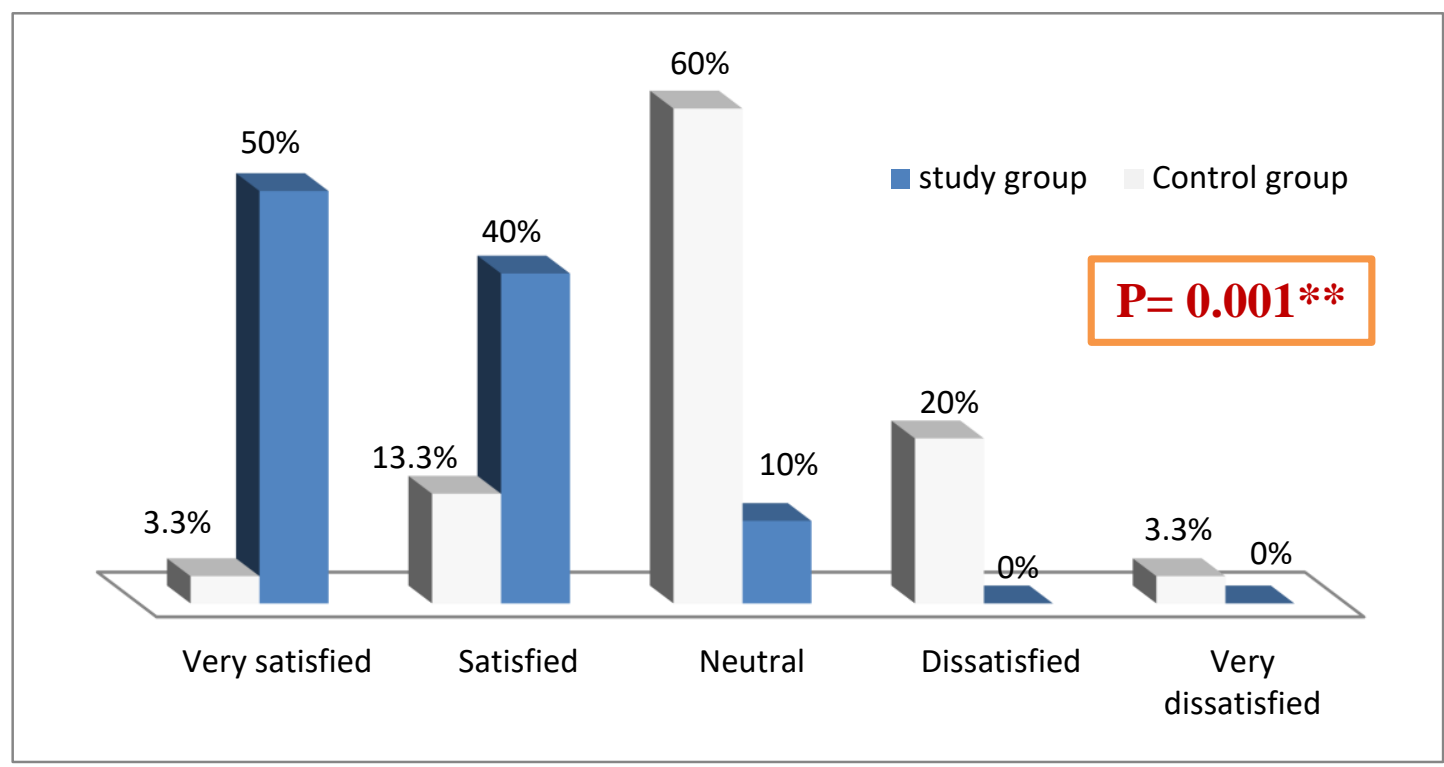

Figure (1): Illustrates patient satisfaction level for study and control group patients.

Table (1): Showed that, about two thirds $(63.3 \%)$ of study group were males and $(56.7 \%)$ of control group were females. $(60.0 \%)$ of both groups were in the age group of 51 to 60 years old with a mean of $(51.7 \pm 8.7)$ and (50.3 \pm 9.6$)$ respectively.also there were majority patients in both study group and control groups being married $(86.7 \%)$.As well highest percentage of both groups was diagnosed as congestive heart failure with ischemic heart disease. In relation to allergies, (36.7\%) of both groups patients had food allergy with no statistical significant differences among both group subjects in all table items. 
Table (2): As for anxiety level it was observed that there was improvement in decreasing anxiety level at $4^{\text {th }}$ and $6^{\text {th }}$ days after intervention in study group patients with statistical significant differences among study and control group patients with $\mathrm{p}$ value at $(0.012 *$ and $0.001 * *)$ respectively. Thus, hypothesis one was supported.

Table (3): Illustrated the distribution between study and control as regards to patient satisfaction about hospital administrative care; where, care included four items, there was no statistical significant difference among study and control groups in relation to (Admission process to hospital was completed smoothly without any difficulties, and clear information at all times, what was happening while waiting to be admitted to coronary care unit).But there were significant difference among study and control groups concerning to patient family was kept well informed about patient condition and needs and discharge arrangement was handled smoothly with $\mathrm{p}$ value $=(0.000 * *)$.Thus, hypothesis two was partially supported.

Table (4): Demonstrated the comparison between study and control as regards to patient satisfaction about caring process by nursing team; there was statistical significant difference among study and control group patients in all items of care by nursing team with $\mathrm{p}$ value $=\left(0.000^{* *}\right)$. Thus, hypothesis two was supported.

Table (5): Showed the distribution between study and control as in relation to satisfaction about caring process by medical team; there was statistical significant difference among study and control groups in relation to one item only called (patient received sufficient information concerning my medical condition from admission) with $\mathrm{p}$ value $=(0.000 * *)$. But the other two items there was no significant difference among study and control group subjects. Thus, hypothesis two was partially supported.

Table (6): Clarified the comparison between study and control as regards to patient satisfaction about caring process to achieve hospital outcomes; where, there was statistically significant difference among study and control group patients with $\mathrm{p}$ value $=\left(0.000^{* * *}\right)$. Thus, hypothesis one was supported.

Figure(1): Displayed distribution for patient satisfaction level about caring process for each study and control. This table reveals that there were statistically significant association between study and control groups regarding to patient overall satisfaction level with $p$ value $(p<0.05)$.Thus increased satisfaction level associated with the study group Thus, hypothesis two was supported.

\section{Discussion}

Clinical pathway is the heart of quality and patient safety. It is of major importance to guide multidisciplinary teams- including clinicians, managers and patients. The aim of a care pathway is to enhance the quality of care across the continuum of care by improving patient outcomes, promoting patient safety, increasing patient satisfaction, and integration of knowledge, skills, and experience of the nurse that will optimize outcomes of the patient, family, nurse, and hospital system. Clinical pathways developed primarily for high volume hospital diagnosis, display goals for patients and provide the corresponding ideal sequence and timing of staff action for achieving those goals with optimal efficiency (Panella \& Vanhaecht, 2010).

So, the main aim of this research was to determine effect of modified clinical pathway guidelines for congestive heart failure critically ill patients' satisfaction. Where, the key result was to decrease anxiety level, and increase patient \&family satisfaction. The current study compared study group, that followed modified clinical pathway guidelines checklist in addition to hospital routine care and the control group that undergo the routine hospital care only.

\section{As regards to background data}

The findings of current study illustrated that there were no statistical significant differences among both groups regarding basic data upon admission which include age, sex, marital status, level of education, and occupation. The study sample included sixty patients, 30 patients in each group. The mean age for study subjects (study and control) was $(51.7 \pm 8.7 \&$ $50.3 \pm 9.6)$ respectively, was no significant difference between two groups.

The present study was supported with Karapolat et al., (2008) who reported that thirty nine CHF patients were involved in the study with average age of CHF patients was $(45.51 \pm 14.42)$ years. Also, Pourmoghaddas et al., (2014) told that a study with total number of sixty patients with $\mathrm{CHF}$ were enrolled in the research, thirty participants in study group and thirty participants in control group with mean age $(50.70 \pm 12.5-54.47 \pm 14.6)$ respectively.

Study by Robinet et al., (2018) who reported that more males' patients are admitted to intensive care units than females patients, with men accounting for about two thirds of the admission. The reasons behind this difference have been explained by the possible immunological effects of sex hormones.

\section{As regards to anxiety level}

The current study illustrated that there was decreasing in the anxiety level in the study group with significantly lower level compared with control group on discharge. This can be related to 
psychological support information about caring process given to study group patients from admission and the orientation by modified clinical pathway guidelines compared with to control group patients. Additionally, discharge instructions and booklet handout given to patients before discharge may decrease their worries about what expect and what to do after discharge.

Findings of the present study in agree with Mohamed, (2016) that observed that significantly lower level of anxiety on the study group patient as compared to control group during discharge. This may be related to application of multi-disciplinary interventions as pulmonary and psychological rehabilitation practices, coughing and breathing exercise, information given to study group during admission and instruction about caring process during hospital periods, furthermore discharge instruction and booklet handout given to patients before discharge may decrease their worry about what to expect and what to do after discharge.

Also Abd-Elwanees, (2014) who revealed that, there was a decrease in anxiety level at day of discharge for study and control group and the level of decreasing in study group was higher than its level in the control group. Where the anxiety level decreased from (severe to mild) for study group but the anxiety level reduced from (severe to moderate) for control group patients, the improvement of anxiety level for the study group may be due to the application of the clinical pathway which involved pulmonary and psychological rehabilitation practices. This pathway contains psychological care and educational sides concerning anxiety practice. On the contrast the control group patients received routine care without concentrating on patient's psychological problems.

Also the findings of current study was agreed with Ahmed, (2014) that reported reduced level of anxiety in study group who received phase one CR when compared to control group. This improvement caused by intervention practices made by the researcher.

\section{Regarding to patient satisfaction}

In the present study, the patient's satisfaction questionnaire was designed to seek feedback from patients of both groups on all phases of patient care services and interventions. The findings of the current study illustrated statistical significant difference among both group patients regarding to all aspects for patient satisfaction. This finding is mostly related to the educational session by explanation for all items care process on and comprehensive education with colored booklet before discharge from (CCU) given to study group patients. Furthermore significant improvement of psychological status and decrease in anxiety level most appropriately play a significant role in increased patients' satisfaction level.
Current study also revealed that study group had higher satisfaction level as compared with the control group. The results of present study are consistent with Verdu et al., (2009), who tried to measure patient satisfaction with a questionnaire carried out at the day of discharge and found that, the satisfaction indictor reached up to two third.

Also our results gone well together with other studies that have shown that the implementation of clinical pathway had positive effects on patients' satisfaction. Shalaby, (2010) found a significant improvement in the overall patients' satisfaction after implementing the clinical pathway for patient with Valvular heart surgery where the overall satisfaction was very satisfied with $99 \%$ of the pathway group compared with $89 \%$ of the control group.

The findings of present study are in contrast with Nick et al., (2003) who reported that, no statistical difference in total patient satisfaction among two group patients. When the groups were compared with every satisfaction dimension, study group were satisfied. Result was consequence of lesser cores in pathway group in relation to their participation in decision making for their care and communication processes. Control group scores revealed a slow rise, while pathway group documented rise among satisfaction admission and discharge. It isn't clear why these scores had reduced for study group. Possible causes for finding contain that there might be a memory consequence influencing scores. On the other hand, if this was the case then it could be predictable to affect two groups given their demographic similarity.

Finally, critically ill heart failure patients have benefit from early diagnosis, close monitoring and management providing by skilled teams that contain a specialist heart failure nurse and cardiology nurses with appropriate education to support harmless practice (Riley, 2015).

\section{Conclusion}

By combining all possible findings of implementation modified clinical pathway guidelines, it can be concluded that care modified clinical pathway guidelines to congestive heart failure management revealed well psychological intervention that reduce anxiety level with statistical significant difference between both groups, also increased patient satisfaction level about caring process among the study group patients as compared with the control group patients.

\section{Recommendation suggested}

- Conducting training programs about importance of modified clinical pathway guidelines implementation for all health care providers.

- Conducting regular briefing sessions for clinical pathway team on order to improve implementation 
of the clinical pathway and coordinated care process to minimize inefficiency.

- Integrate the clinical pathway program as a daily part of care with clearly planned objectives and outcomes.

- Reapply this research in different geographical locations with a larger probability sample for generalization.

\section{References}

1. Abd-Elwanees A., (2014): Effect of Implementing Clinical Pathway on the Clinical Outcomes of Patients with Acute Exacerbations of Chronic Obstructive Pulmonary Disease International Journal of Nursing Science 2014, 4(1): $1-10$

2. Ahmed S., Helmy H., \& Abdel Aziz M., (2014): Impact of phase one; cardiac rehabilitation on early complication of patients with ST segment-elevation acute myocardial infarction in coronary care unit, (unpublished master thesis), faculty of nursing, Assuit University, pp. 71-93.

3. Bruce G., (2011): Assessment Chart for Pitting Edema adapted from the Guelph General Hospital Congestive Heart Failure clinical Pathway New York Heart Association. November 1; PP 1-7.

4. Canadian Cardiovascular Society (CCS) Consensus Conference recommendations on heart failure (2006): Diagnosis and management, Congestive Heart Failure by the Heart and Stroke Foundation, Heart Failure: Patient Information Booklet by the University of Ottawa Heart Institute and Congestive Heart Failure Clinic pamphlet; Queensway Carleton Hospital; PP, 1-24.

5. Chen-Scarabelli C., Saravolatz L., Hirsh B., Agrawal P., Tiziano M., (2015):Dilemmas in end-stage heart failureJournal of Geriatric Cardiology 12: PP 57-65.

6. Debasree D., Smita K., Nitin K., James G., (2013): Depression and Anxiety in Heart Failure Patients in a South Indian Population: A Pilot Study Asian Journal of Biomedical and Pharmaceutical Sciences 3(17), PP 65-70.

7. DeMartino, J., \& Larsen, J., (2012): Equity in cancer care: pathways, protocols, and guidelines, JNCCN Journal of the National Comprehensive Cancer Network.

8. Gonce P., Dorrie K., (2013): Essentials of critical care nursing a holistic approach. Wolters Kluwer Health, Lippincott Williams \&Wilkins, $9^{\text {th }}$ ed, chapter 14 p 194.

9. Goodrick D., (2014): Comparative Case Studies, Methodological Briefs: Impact
Evaluation 9, UNICEF Office of Research, Florence. Effectiveness and Quality of Treatment of Cancer and Rheumatoid Arthritis" (2014): http://ir.cardinalhealth.com/news/newsdetails/Ne w-Studies Show-Cardinal-Health-SpecialtySolutions-Clinical-Pathways-Improve-CostEffectiveness-and-Quality-of-Treatment-ofCancer-and-Rheumatoid-Arthritis/default.aspx

10. Julian L., (2011): Measure of anxiety: StateTrait Anxiety Inventory, published by Wiley online library volume 63, issue S11 PP 1-5. Available on: http://circ.ahajou3r4n5al2s.org/ by guest on January 22, 2018.

11. Karapolat H., Eyigor S., Atasever A., Zoghi M., Nalbantgil S., \& Durmaz B., (2008): Effect of dyspnea and clinical variables on the quality of life and functional capacity in patients with chronic obstructive pulmonary disease and congestive heart failure Chinese Medical Journal; 121 (7): 592-596.

12. Kinsman L., Rotter T., James E., Snow P., \& Willis J., (2010): What is a clinical pathway? Development of a definition to inform the debate, BMC Medicine, 8(31), 1-3

13. Mohamed M., Alaa S., Ali G., (2016): Effect of applying clinical pathway for congestive heart failure on their health status outcomes [Doctorate unpublishedThesis] Suez Canal: faculty of nursing, Suez Canal University.

14. Nick S., Houghton L., Kimmel L., Graham A., (2003): Clinical pathways for fractured neck of femur: a cohort study of heath related quality of life, patient satisfaction and clinical outcome, Australian Journal of Advanced Nursing Volume 20 Number 3 pp. 24-29.

15. Panella M., Vanhaecht K., (2010): IS there still need for confusion about pathways? International journal of care pathway, Vol, 14, pp: 1-3

16. Pourmoghaddas M., Rabbani M., Shahabi J., Garakyaraghi M., Khanjani R., Hedayat P., (2014): Combination of atorvastatin/coenzyme Q10 as adjunctive treatment in congestive heart failure: A double-blind randomized placebocontrolled clinical trial, ARYA Atheroscler; Volume 10, Issue 1 pp. 1-5. www.mui.ac.ir 14 Jan. Pp. 45-50.

17. Rashad E., (2011): The effect of the application of clinical pathway on postoperative outcomes of patients undergoing percutaneous nephrolithotomy, Alexandria: unpublished DSN dissertation, faculty of nursing, Alexandria University.

18. Riley J., (2015): The Key Roles for the Nurse in Acute Heart Failure Management, Radcliffe Cardiology, P.P 123-127. 
19. Robinet P., Milewicz D., Cassis L., Leeper N., Lu H., Smith J., (2018): Consideration of Sex Differences in Design and Reporting of Experimental Arterial Pathology Studies, American Heart Association, Inc. Arterioscler Thromb VascBiol is available on http://atvb.ahajournals.org

20. Salisbury C., Burgess A., Lattimer V., Heaney D., Walker J., Smith H., (2005): Developing a standard short questionnaire for the assessment of patient satisfaction with outof-hours primary care. Family practice, vol, 22, pp. 560-569

21. SevalKul, (2012): Effects of care pathways on the in-hospital treatment of heart failure: a systematic review, BMC Cardiovascular Disorders, 12:81 doi: 10.1186/1471-2261-1281. Available on: http://www.biomedcentral.com/14712261/12/81Accessed at: 22/5/2017.

22. Shalaby S., (2010). The outcome of implementing a clinical pathway for patients undergoing valvular surgery, [Doctorate unpublished Thesis] Alexandria: Alexandria University.

23. Smita K., Nitin K., James G., (2013): Depression and Anxiety in Heart Failure Patients in a South Indian Population: A Pilot Study Asian Journal of Biomedical and Pharmaceutical Sciences 3(17), 65-70.

24. Tang W., Soong C., Lim W., (2013): Patient Satisfaction with Nursing Care: A Descriptive Study Using Interaction Model of Client Health Behavior, International Journal of Nursing Science 2013, 3(2): 51-56 DOI: 10.5923/j.nursing.20130302.04.

25. Verdu A., Maestre A., Lopez P., Gil V., Martin-Hidaalgo A., Castano J., (2009): Clinical pathways as a healthcare tool: design, implementation and assessment of a clinical pathway for lower-extremity deep venous thrombosis. QualSaf Health Care; 18:314-20. 